\title{
SLUDGE-ACTIVATED CARBONS FOR COPPER REMOVAL FROM AQUEOUS SOLUTIONS*
}

\author{
Amilton Feliciano Castro ${ }^{1}$ \\ Irineu Antônio Schadach de Brum² \\ Glaydson Simões dos Reis ${ }^{3}$ \\ Carlos Hoffmann Sampaior ${ }^{4}$ \\ Eder Claudio Lima ${ }^{5}$
}

\begin{abstract}
In this work, activated carbons (ACs) were prepared using Sewage sludge as starting material. The ACs were pyrolyzed in an inert atmosphere at $550{ }^{\circ} \mathrm{C}$ after independent chemical treatment with $\mathrm{ZnCl}_{2}$ or $\mathrm{KOH}$ with ratio of $1: 1$. The materials were used as adsorbents for removal of $\mathrm{Cu}(\mathrm{II})$ from aqueous solutions. The adsorbents were characterized using adsorption/desorption nitrogen isotherm, SEM (scanning electron microscopy). The results showed that copper removal could be linked to surface $\mathrm{pH}$ and compounds present on the surface of adsorbent. $\mathrm{KOH}$-treated adsorbent has smaller surface area $\left(186 \mathrm{~m}^{2} \mathrm{~g}^{-1}\right)$ than $\mathrm{ZnCl}_{2}$-treated adsorbent $\left(192 \mathrm{~m}^{2} \mathrm{~g}^{-1}\right)$, however, $\mathrm{KOH}$-treated adsorbent exhibited higher removal of $\mathrm{Cu}(\mathrm{II})$. The performance of $\mathrm{KOH}$-treated adsorbent could be attributed to the presence of basic groups on the adsorbent surface. Liu isotherm model gave the best description of the equilibrium data. From the Liu isotherm, the maximum adsorption capacities at $298 \mathrm{~K}$ for $\mathrm{KOH}$-treated, $\mathrm{ZnCl}_{2}$-treated and sewage sludge (without inorganic activation) adsorbents are $31.85,19.79$ and $3.513 \mathrm{mg} \mathrm{g}^{-1}$, respectively. The best desorption experiment was obtained using $1.50 \mathrm{~mol} \mathrm{~L}^{-1}$ of $\mathrm{HNO}_{3}$ as eluent. Recoveries of $\mathrm{Cu}(\mathrm{II})$ from $\mathrm{Cu}(\mathrm{II})$-loaded adsorbents are 98.9\% ( $\mathrm{ZnCl}_{2}$-treated) and 95.5\% (KOH-treated.
\end{abstract}

Keywords: Sewage sludge; Pyrolysis; Adsorption; Isotherm; Heavy metal.

1 Engenheiro de Minas, Mestrando PPGE3M, Universidade Federal do Rio Grande do Sul, Porto Alegre, Rio Grande do Sul Brasil.

2 Engenheiro de Minas, Dr.-Ing, Professor, Departamento de Metalurgia, Universidade Federal do Rio Grande do Sul, Porto Alegre, Brasil.

3 Engenheiro Ambiental, Mestre em Engenharia Civil e Ambiental, Doutorando em Engenharia de Minas, Metalúrgica e de Materiais, Universidade Federal do Rio Grande do Sul, Porto Alegre, Brasil.

4 Engenheiro de Minas, Dr.-Ing, Professor, Departamento de Metalurgia, Universidade Federal do Rio Grande do Sul, Porto Alegre, Brasil.

5 Químico, Doutor, Professor, Instituto de Química, Universidade Federal do Rio Grande do Sul, Porto Alegre, Brasil. 


\section{INTRODUCTION}

Metal industries generate enormous amounts of wastewaters that contain toxic species. These toxic species are hazardous to the environment and human health [1]. Heavy metals, non-biodegradable and bioaccumulative substances, are the most toxicological relevance species present in the effluents from metallurgical industries [1]. Copper is used in plating, mining and petroleum refining industries that produce a great amount of wastewater and sludge containing a high concentration of copper cations, which have detrimental effects on the water resources [1]. Therefore, it is essential to remove these toxic substances from wastewaters before being disposed into water bodies.

The major methods for removal of toxic substances include membrane filtration, chemical precipitation, ion exchange and adsorption on activated carbon and silica. However, some of these methods are costly [2]. In recent years, many studies have reported the use of low-cost adsorbents for the removal of toxic substances from wastewater [3]. Adsorbents, such as activated carbon, have wider applications in industries for removal of toxic substances. They can be produced from different kinds of carbon sources such as agricultural wastes and woods [2,3].

The usage of wastes for preparing adsorbents for removal of toxic substances from wastewaters has become extremely attractive because it is economical [2,3]. This strategy is beneficial to the environment because valorization of by-products contributes to the minimization, recovery and reuse of waste. Research work focused on the preparation of adsorbents from sewage sludge should be understood within this scenario. The sludge is perhaps the most pressing problem related to water treatment systems at this time, which is on the increase all over the world [4].

Sludge-based adsorbents have been used for removal of heavy metals, pharmaceuticals and dyes [2-4]. Municipal sewage sludge, which is regarded as ecological burden in the society, is a waste produced from numerous domestic and industrial activities. Its accumulation is undesirable and has no economic value. It will be of interest if this waste could be used for constructive purposes.

The aims of this work are to find more effective adsorbents for the removal of heavy metals (such as $\mathrm{Cu}(\mathrm{II})$ ) and to explore the use of municipal sewage sludge as a raw material, precursor, for production of activated carbons for the removal of $\mathrm{Cu}$ (II) from aqueous solutions. Similarly, the recovery of $\mathrm{Cu}(\mathrm{II})$ from adsorbents through desorption study was investigated.

\section{MATERIAL AND METHODS}

\subsection{Preparation of sewage sludge derived adsorbents}

The raw material used for the preparation of the adsorbents used in this study was the sewage sludge obtained from a municipal wastewater treatment plant in Porto Alegre, RS - Brazil. The sludge was dried at $105^{\circ} \mathrm{C}$ for $24 \mathrm{~h}$ until the weight loss was constant. The sludge was subsequently crushed with a grinder and sieved to particle size below $250 \mu \mathrm{m}$.

The sludge-based adsorbents were prepared using the following procedure: a $50.0 \mathrm{~g}$ of powdered sewage sludge, a $50.0 \mathrm{~g}$ of inorganic component $(\mathrm{KOH})$ and $10.0 \mathrm{~mL}$ of water were properly mixed to obtain a homogeneous paste. The paste was placed in a crucible and dried at room temperature for $24 \mathrm{~h}$. Subsequently, the sample was placed in the pyrolysis furnace under inert atmosphere with gas (argon) exchange 
rate at $100 \mathrm{~mL} \mathrm{~min}^{-1}$ to produce carbon adsorbents. The crucibles were heated in the tubular furnace at $10 \mathrm{~K} \mathrm{~min}^{-1}$ up to $823 \mathrm{~K}$ for $60 \mathrm{~min}$. The adsorbent was later cooled down to room temperature under inert atmosphere, milled, sieved to particle size $\leq$ $200 \mu \mathrm{m}$ and stored in an airtight container until use. The carbon adsorbent was named $\mathrm{KOH}$-activated adsorbent.

The same procedure was used to prepare $\mathrm{ZnCl}_{2}$-activated adsorbent (sewage sludge: $\mathrm{ZnCl}_{2}$ was $1: 1$ ). The carbon adsorbents was labeled $\mathrm{ZnCl}_{2}$-activated adsorbent.

For comparison, a carbon adsorbent, without inorganic components, with particle size $\leq 150 \mu \mathrm{m}$ was also prepared. This carbon adsorbent was only pyrolyzed and named as sewage sludge (without inorganic activation).

Prior batch adsorption experiments for the three adsorbents, a $10.0 \mathrm{~g}$ of adsorbent and $150 \mathrm{~mL}$ of $6 \mathrm{~mol} \mathrm{~L}^{-1} \mathrm{HCl}$ were placed in a $250 \mathrm{~mL}$ boiling flask to complete the chemical activation of the carbon adsorbent (Ribas et al. 2014). The mixture was stirred and refluxed for $2 \mathrm{~h}(343 \mathrm{~K})$ on a magnetic stirrer. The solid material was adequately washed with deionized water, oven dried at $383 \mathrm{~K}$ for $5 \mathrm{~h}$, milled to particle sizes $\leq 150 \mu \mathrm{m}$ and kept until use.

\subsection{Characterization of adsorbents}

The adsorbents were analyzed using scanning electron microscopy, SEM (JEOL microscope, model JSM 6060).

The $\mathrm{N}_{2}$ adsorption/desorption isotherms of the adsorbents were carried out using a surface analyzer (Micrometrics Instrument, TriStar II 3020). The specific surface areas were determined using Brunauer, Emmett and Teller (BET) technique.

\subsection{Metallic ion solution}

A $1000 \mathrm{mg} \mathrm{L}^{-1}$ stock solution of $\mathrm{Cu}$ (II) was prepared by dissolving suitable amounts of analytical grade of $\mathrm{CuSO}_{4} .5 \mathrm{H}_{2} \mathrm{O}$ in deionized water. Working metal solutions (10.00 $400.0 \mathrm{mg} \mathrm{L}^{-1}$ ) were prepared from serial dilution of the stock solution. The $\mathrm{pH}$ of solutions was fixed at 6.0. The $\mathrm{Cu}$ (II) concentration was measured using PerkinElmer Flame Atomic Absorption Spectrometer.

\subsection{Batch adsorption experiments}

A $20.00 \mathrm{~mL}$ of $10.00-400.0 \mathrm{mg} \mathrm{L}^{-1}$ of $\mathrm{Cu}$ (II) at $\mathrm{pH} 6.0$ were added to plastic tubes containing $80.0 \mathrm{mg}$ of adsorbent. The flasks were capped, and placed horizontally in a Tecnal shaker, and the system was agitated for 360 min. Afterwards, the flasks were centrifuged using Fanem centrifuge) to separate the adsorbent from the aqueous solutions. The final concentrations of the $\mathrm{Cu}(\mathrm{II})$ were determined using FAAS. The amount of $\mathrm{Cu}(\mathrm{II})$ removed by adsorbent is given by the Equation 1 .

$$
q=\frac{\left(C_{o}-C_{f}\right)}{m} . V
$$

Where $\mathrm{q}$ is the amount of $\mathrm{Cu}(\mathrm{II})$ removed by adsorbent $\left(\mathrm{mg} \mathrm{g}^{-1}\right) ; \mathrm{C}_{\mathrm{o}}$ is the initial $\mathrm{Cu}(\mathrm{II})$ concentration, which was in contact with adsorbent $\left(\mathrm{mg} \mathrm{L}^{-1}\right) ; \mathrm{C}_{f}$ is the $\mathrm{Cu}(\mathrm{II})$ concentrations ( $\mathrm{mg} \mathrm{L}^{-1}$ ) after the batch adsorption process; $\mathrm{V}$ is the volume of $\mathrm{Cu}(\mathrm{II})$ solution ( $\mathrm{L}$ ) in contact with the adsorbent; and $\mathrm{m}$ is the mass $(\mathrm{g})$ of adsorbent. 


\subsection{Statistical evaluation of models}

The equilibrium data was fitted using nonlinear methods with successive interactions calculated by the Levenberg-Marquardt method. Interactions were computed with the aid of the Simplex method, based on the nonlinear fitting facilities of the Microcal Origin 9.0 software. A determination coefficient $\left(R^{2}\right)$, an adjusted determination coefficient $\left(R^{2}\right.$ adj) and the standard deviation (SD) were jointly used to evaluate the suitability of the models $[2,3,5]$. The standard deviation is defined as a measure of the differences between the theoretical and experimental amounts of metallic ion adsorbed.

The $R^{2}, R^{2}$ adj and SD can be represented by Equations 3, 4 and 5, respectively.

$$
\begin{aligned}
& R^{2}=\left(\frac{\sum_{i}^{n}\left(q_{i, \text { exp }}-\bar{q}_{i, \text { exp }}\right)^{2}-\sum_{i}^{n}\left(q_{i, \text { exp }}-q_{i, \text { model }}\right)^{2}}{\sum_{i}^{n}\left(q_{i, \text { exp }}-\bar{q}_{i, \text { exp }}\right)^{2}}\right) \\
& R_{\text {adj }}^{2}=1-\left(1-R^{2}\right) \cdot\left(\frac{n-1}{n-p-1}\right) \\
& S D=\sqrt{\left(\frac{1}{n-p}\right) \cdot \sum_{i}^{n}\left(q_{i, \text { exp }}-q_{i, \text { model }}\right)^{2}}
\end{aligned}
$$

In these equations, $q_{i, \text { model }}$ represents individual theoretical $q$ value predicted by the model; $q_{i, \exp }$ represents individual experimental $q$ value, $\bar{q}_{\text {exp }}$ is the average of experimental $q, n$ represents the number of experiments while $p$ represents the number of parameters in the fitting model $[2,3,5]$.

\subsection{Equilibrium models}

Langmuir, Freundlich and Liu models, as shown in Equations 9, 10 and 11, respectively, were used to analyze equilibrium data.

$q_{e}=\frac{Q_{\max } \cdot K_{L} \cdot C_{e}}{1+K_{L} \cdot C_{e}}$

$q_{e}=K_{F} \cdot C_{e}^{1 / n_{F}}$

$q_{e}=\frac{Q_{\max } \cdot\left(K_{g} \cdot C_{e}\right)^{n_{L}}}{1+\left(K_{g} \cdot C_{e}\right)^{n_{L}}}$

Where $q_{e}$ represents the amount adsorbate adsorbed at the equilibrium $\left(\mathrm{mg} \mathrm{g}^{-1}\right)$; $Q_{\max }$ represents the maximum adsorption capacity of the adsorbent $\left(\mathrm{mg} \mathrm{g}^{-1}\right) ; K_{L}$ represents the Langmuir equilibrium constant $\left(\mathrm{L} \mathrm{mg}^{-1}\right) ; C_{e}$ represents equilibrium dye concentration $\left(\mathrm{mg} \mathrm{L}^{-1}\right) ; K_{F}$ represents the Freundlich equilibrium constant $\left[\mathrm{mg} \mathrm{g}^{-1}(\mathrm{mg}\right.$ $\left.\left.\mathrm{L}^{-1}\right)^{-1 / n F}\right] ; n_{F}$ is a dimensionless exponent of the Freundlich equation; $K_{g}$ represents the Liu equilibrium constant $\left(\mathrm{L} \mathrm{mg}^{-1}\right)$; and $n_{L}$ represents a dimensionless exponent of the Liu equation.

\subsection{Desorption experiments}

Desorption studies help to elucidate the mechanism of adsorption, regeneration of adsorbent, and recovery of adsorbate from the spent adsorbent apart from protecting the environment from solid waste disposal problems. Batch desorption studies were 
carried out by agitating a $20.0 \mathrm{~mL}$ of $100.0 \mathrm{mg} \mathrm{L}^{-1} \mathrm{Cu}(\mathrm{II})$ solution with $80.0 \mathrm{mg}$ of carbon adsorbent for $240 \mathrm{~min}$. The liquid phase was separated from the solid phase. Then, metallic loaded adsorbents were agitated with a $20.0 \mathrm{ml}$ of aqueous solutions (0.10-1.50 mol L-1 $\mathrm{HCl}$ or $0.10-1.50 \mathrm{~mol} \mathrm{~L}^{-1} \mathrm{HNO}_{3}$ ) for $1 \mathrm{~h}$.

\section{RESULTS AND DISCUSSION}

The scanning electron microscopy (SEM) images of the sludge-based adsorbents are given in Figures $1 \mathrm{a}, \mathrm{b}$ and $\mathrm{c}$. As shown in Figure 1a, there is no enough and successful pore development in the adsorbent obtained with pyrolysis without chemical activation. However, the chemical activation with $\mathrm{KOH}$ and $\mathrm{ZnCl}_{2}$ (Figures $1 \mathrm{~b}$ and $\mathrm{c}$ ) increases the roughness compared to the untreated sample (Figure 1a). The sludge-based adsorbents obtained by chemical activation have a regular and highly porous surface, indicating higher surface area that is responsible for higher amount of $\mathrm{Cu}(\mathrm{II})$ adsorbed from aqueous solutions.
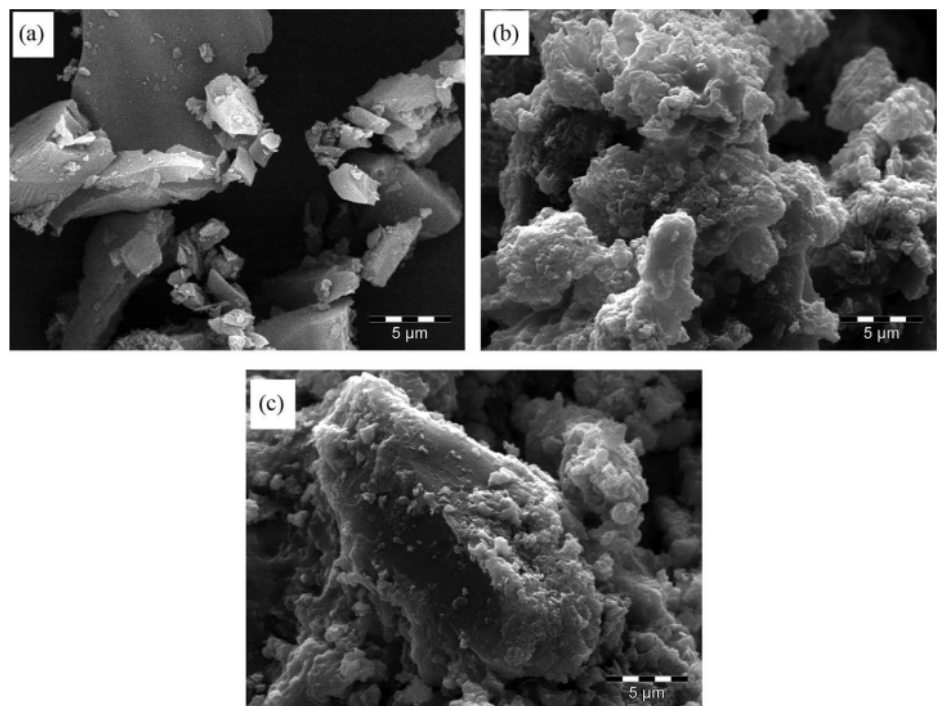

Figure 3. Scanning electron micrographs of (a) sewage sludge without activation; (b) $\mathrm{ZnCl} 2$-treated sludge; and (c) $\mathrm{KOH}$-treated sludge.

The textural properties such as surface area and pore volume of sewage sludge and adsorbents are shown in Table 1. The surface area of pyrolyzed materials without chemical treatment and with chemical treatment $\left(\mathrm{ZnCl}_{2}\right.$ and $\left.\mathrm{KOH}\right)$, under $\mathrm{N}_{2}$ at 550 ${ }^{\circ} \mathrm{C}$ and hold time of $60 \mathrm{~min}$, were evaluated. The values of specific surface areas of $\mathrm{ZnCl}_{2}$-activated and $\mathrm{KOH}$-activated adsorbents are similar. The specific surface areas of the chemically treated adsorbents are much higher than that of sewage sludge (without inorganic activation) - an indication that chemical activation improved the textural characteristics of $\mathrm{ZnCl}_{2}$-activated and $\mathrm{KOH}$-activated adsorbents. 
Table 2. Textural properties of adsorbents.

\begin{tabular}{lccc}
\hline Properties & $\begin{array}{c}\mathrm{KOH} \text {-treated } \\
\text { adsorbent }\end{array}$ & $\begin{array}{c}\mathrm{ZnCl}_{2} \text {-treated } \\
\text { adsorbent }\end{array}$ & $\begin{array}{c}\text { Sewage sludge } \\
\text { (without inorganic } \\
\text { activation) }\end{array}$ \\
\hline Specific surface area $\left(\mathrm{m}^{2} \mathrm{~g}^{-1}\right)$ & 186 & 192 & 25.5 \\
Total pore volume $\left(\mathrm{cm}^{3} \mathrm{~g}^{-1}\right)$ & 0.112 & 0.158 & 0.070 \\
\hline
\end{tabular}

The disparities in textural properties could be linked to differences in the methods of impregnation. Ros et al. [6] reported that dry bleeding using $\mathrm{KOH}$ could increase the efficiency and the surface area better than the impregnation done by humid method. Similarly, the same researchers reported that different surface areas found in literature could be related to different types of raw materials used (sewage sludge), and that raw materials with higher carbon content might produce adsorbents with higher surface areas $[6,7]$.

\subsection{Chemical activation with $\mathrm{ZnCl}_{2}$}

$\mathrm{ZnCl}_{2}$ is one of the most effective chemical activation reagents for sewage sludge $[6,7]$. In these studies the highest specific surface area was achieved by the chemical activation with $\mathrm{ZnCl}_{2}$. These authors reported surface area up to $647 \mathrm{~m}^{2} \mathrm{~g}^{-1}$, however, in this work the surface area is $192 \mathrm{~m}^{2} \mathrm{~g}^{-1}$. The characteristics of the sewage sludge utilized might be a significant factor for explaining the large surface area achieved [7]. The diversity of optimum activation conditions is reflected in the variety of mechanisms by which $\mathrm{ZnCl}_{2}$ can develop porosity. $\mathrm{ZnCl}_{2}$ is generally believed to act as a dehydrating agent and as a tar formation suppressant [4].

\subsection{Chemical activation with $\mathrm{KOH}$}

$\mathrm{KOH}$ is an effective activating reagent for production of activated (Ros et al. 2006; Gasco et al. 2005). The highest surface areas reported in the literature are $1882 \mathrm{~m}^{2}$ $\mathrm{g}^{-1}$ and $1686 \mathrm{~m}^{2} \mathrm{~g}^{-1}[6,7]$. However, in the present work the surface area is $186 \mathrm{~m}^{2} \mathrm{~g}^{-1}$ (Table 1) - low values compared with literature values. A possible explanation for the discrepancy in these values could be traced to pyrolysis conditions under which the samples were produced [4-7]

\subsection{Equilibrium studies}

An adsorption isotherm describes the relationship between the amount of adsorbate removed by the adsorbent and the adsorbate concentration left in the solution. There are many equations for analyzing equilibrium data of experimental adsorption. The parameters of these equilibrium models provide useful insights into the adsorption mechanism, the surface properties and affinity of the adsorbent.

Figure 4 and Table 2 present respective curves and fitting parameters adsorption isotherms of $\mathrm{Cu}(\mathrm{II})$ onto Sewage sludge (without inorganic activation), $\mathrm{KOH}$-treated and $\mathrm{ZnCl}_{2}$-treated adsorbents. 


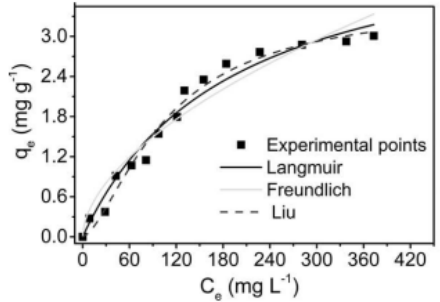

(a)

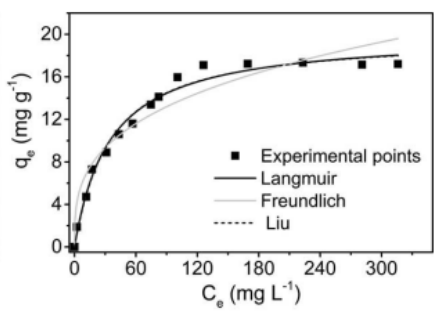

(b)

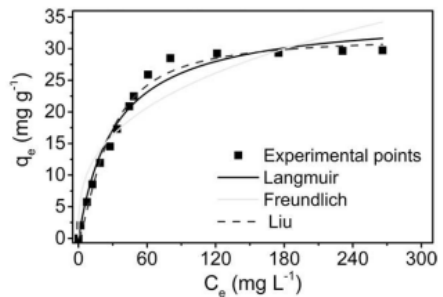

(c)

Figure 4. Langmuir, Freundlich, and Liu adsorption isotherm models for $\mathrm{Cu}(\mathrm{II})$ removal by (a) sewage sludge without activation; (b) $\mathrm{ZnCl} 2$-treated sludge; and (c) $\mathrm{KOH}$-treated sludge.

Table 2. Isotherm parameters for $\mathrm{Cu}(\mathrm{II})$ adsorption using sewage sludge (without inorganic activation), $\mathrm{KOH}$-treated and $\mathrm{ZnCl}_{2}$-treated adsorbents. Conditions: temperature, $25^{\circ} \mathrm{C} ; \mathrm{pH} 6.0$; contact time, $4 \mathrm{~h}$; adsorbent mass, $80.0 \mathrm{mg}$.

\begin{tabular}{|c|c|c|c|}
\hline 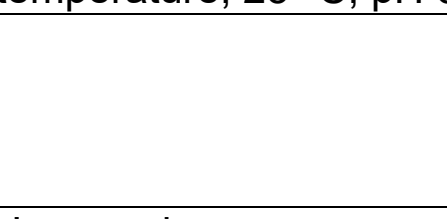 & $\begin{array}{l}\text { Sewage sludge } \\
\text { (without } \\
\text { inorganic } \\
\text { activation) }\end{array}$ & $\begin{array}{l}\mathrm{KOH}- \\
\text { treated }\end{array}$ & $\begin{array}{l}\mathrm{ZnCl}_{2-} \\
\text { treated }\end{array}$ \\
\hline \multicolumn{4}{|l|}{ Langmuir } \\
\hline$Q_{\max }\left(\mathrm{mg} \mathrm{g}^{-1}\right)$ & 4.797 & 35.44 & 20.01 \\
\hline $\mathrm{K}_{\mathrm{L}}\left(\mathrm{L} \mathrm{mg}^{-1}\right)$ & 0.00525 & 0.03125 & 0.02891 \\
\hline $\mathrm{R}_{\mathrm{Adj}}$ & 0.9715 & 0.9768 & 0.9848 \\
\hline $\mathrm{SD}\left(\mathrm{mg} \mathrm{g}^{-1}\right)$ & 0.1760 & 1.6257 & 0.7544 \\
\hline \multicolumn{4}{|l|}{ Freundlich } \\
\hline $\mathrm{K}_{\mathrm{F}}\left(\mathrm{mg} \mathrm{g}^{-1}\left(\mathrm{mg} \mathrm{L}^{-1}\right)^{-1 / n} \mathrm{~F}\right)$ & 0.1186 & 5.151 & 3.195 \\
\hline $\mathrm{n}_{\mathrm{F}}$ & 1.775 & 2.948 & 3.173 \\
\hline$R_{\text {Adj }}$ & 0.9398 & 0.8861 & 0.9239 \\
\hline $\mathrm{SD}\left(\mathrm{mg} \mathrm{g}^{-1}\right)$ & 0.2557 & 3.605 & 1.629 \\
\hline \multicolumn{4}{|l|}{ Liu } \\
\hline$Q_{\max }\left(\mathrm{mg} \mathrm{g}^{-1}\right)$ & 3.513 & 31.85 & 19.79 \\
\hline $\mathrm{Kg}_{\mathrm{g}}\left(\mathrm{L} \mathrm{mg}^{-1}\right)$ & 0.009427 & 0.03747 & 0.02954 \\
\hline $\mathrm{nL}$ & 1.542 & 1.421 & 1.031 \\
\hline $\mathrm{R}_{\mathrm{Adj}}$ & 0.9807 & 0.9866 & 0.9836 \\
\hline $\mathrm{SD}\left(\mathrm{mg} \mathrm{g}^{-1}\right)$ & 0.1449 & 1.2356 & 0.7276 \\
\hline
\end{tabular}

The values of standard deviation of the Freundlich model are $0.2557,3.605$ and $1.629 \mathrm{mg} \mathrm{g}^{-1}$ for Sewage sludge (without inorganic activation), $\mathrm{KOH}$-treated and $\mathrm{ZnCl}_{2}$-treated adsorbents, respectively. The standard deviation values for Langmuir model are $0.1760,1.6257$ and $0.7544 \mathrm{mg} \mathrm{g}^{-1}$ while standard deviation values for Liu model are $0.1449,1.2356$ and $0.7276 \mathrm{mg} \mathrm{g}^{-1}$ for Sewage sludge (without inorganic activation), $\mathrm{KOH}$-treated and $\mathrm{ZnCl}_{2}$-treated adsorbents, respectively. Based on the values of standard deviation, the equilibrium of adsorption of $\mathrm{Cu}(\mathrm{II})$ on three 
adsorbents, is best described by Liu isotherm model. The Liu isotherm model shows lower values of standard deviation - an indication that the experimental amounts adsorbed by the adsorbents are closer to those calculated the Liu model.

The maximum adsorption capacities obtained from the Liu isotherm are 31.85, 19.79 and $3.513 \mathrm{mg} \mathrm{g}^{-1}$ for $\mathrm{KOH}$-treated, $\mathrm{ZnCl}_{2}$-treated and sewage sludge (without inorganic activation) adsorbents, respectively.

Although $\mathrm{KOH}$-treated adsorbent has lower surface area than $\mathrm{ZnCl}_{2}$-treated adsorbent, but $\mathrm{KOH}$-activated adsorbent has greater efficiency for the removal of $\mathrm{Cu}$ (II) than $\mathrm{ZnCl}_{2}$-activated adsorbent. This observation could be linked to the presence of basic groups (especially $\mathrm{OH}$ group) on the surface of $\mathrm{KOH}$-activated adsorbent [6-8].

\subsection{Desorption studies}

Regeneration of adsorbents saturated with $\mathrm{Cu}(\mathrm{II})$ was performed at $25^{\circ} \mathrm{C}$ using 0.10 $1.50 \mathrm{~mol} \mathrm{~L}^{-1} \mathrm{HCl}$ and $0.10-1.50 \mathrm{~mol} \mathrm{~L}^{-1} \mathrm{HNO}_{3}$ as eluents. The regeneration efficiencies for $\mathrm{Cu}(\mathrm{II})$ using $1.50 \mathrm{~mol} \mathrm{~L}^{-1} \mathrm{HCl}$ are $92.4 \%$ and $96.7 \%$ for $\mathrm{KOH}$-treated and $\mathrm{ZnCl}_{2}$-treated adsorbents, respectively. For $1.50 \mathrm{~mol} \mathrm{~L}^{-1} \mathrm{HNO}_{3}$, the corresponding efficiencies are $95.5 \%$ and $98.9 \%$ (Table 3 ).

Table 3. Desorption of $\mathrm{Cu}(\mathrm{II})$ from $\mathrm{KOH}$-treated and $\mathrm{ZnCl}_{2}$-treated adsorbents.

Conditions: temperature, $25{ }^{\circ} \mathrm{C}$; contact time, $1 \mathrm{~h}$; adsorbent mass, $80.0 \mathrm{mg}$; and using 0.1-1.5 mol L-1 $\mathrm{HCl}$ and $\mathrm{HNO}_{3}$.

\begin{tabular}{|c|c|c|}
\hline & $\begin{array}{c}\mathrm{KOH} \text {-treated } \\
\text { adsorbent }\end{array}$ & $\begin{array}{c}\mathrm{ZnCl}_{2} \text {-treated } \\
\text { adsorbent }\end{array}$ \\
\hline Eluent & \multicolumn{2}{|c|}{ \%Recovery of $\mathrm{Cu}(\mathrm{II})$} \\
\hline \multicolumn{3}{|c|}{$\mathrm{HCl}\left(\mathrm{mol} \mathrm{L}^{-1}\right)$} \\
\hline 0.10 & 27.8 & 31.4 \\
\hline 0.25 & 37.6 & 44.5 \\
\hline 0.50 & 53.6 & 58.6 \\
\hline 1.00 & 69.5 & 74.2 \\
\hline 1.50 & 92.4 & 96.7 \\
\hline \multicolumn{3}{|c|}{$\mathrm{HNO}_{3}\left(\mathrm{~mol} \mathrm{~L}^{-1}\right)$} \\
\hline 0.10 & 34.8 & 39.3 \\
\hline 0.25 & 49.6 & 53.7 \\
\hline 0.50 & 61.9 & 67.1 \\
\hline 1.00 & 87.7 & 92.4 \\
\hline 1.50 & 95.5 & 98.9 \\
\hline
\end{tabular}

To investigate re-utilization of the regenerated adsorbents, the regenerated adsorbents were employed for metal uptake in a new cycle of adsorption. It was observed that the adsorption capacity was ca. $56 \%$ of the original adsorbents, indicating that adsorbents produced from sewage sludge could be a good alternative adsorbent for $\mathrm{Cu}(\mathrm{II})$ removal from aqueous solutions.

\section{CONCLUSION}

In this work, activated carbons were produced from urban sewage sludge using three different procedures: (1) one single pyrolysis stage (sewage sludge without inorganic 
activation); (2) chemical activation with $\mathrm{ZnCl}_{2}$ ( $\mathrm{ZnCl}_{2}$-activated adsorbent) and (3) $\mathrm{KOH}$ (KOH-activated adsorbent). The sewage sludge-based adsorbents show different surface properties. The $\mathrm{ZnCl}_{2}$-activated adsorbent has higher surface area and larger pore volume than other two adsorbents, however, $\mathrm{KOH}$-activated adsorbent has higher capacity for removal of $\mathrm{Cu}$ (II) from aqueous solutions. The isothermal data were fitted to Liu, Langmuir and Freundlich isotherms models to understand the adsorption process of $\mathrm{Cu}(\mathrm{II})$. The data were best described by Liu model and the maximum adsorption capacities of $\mathrm{Cu}(\mathrm{II})$ are $31.85,19.79$ and 3.513 $\mathrm{mg} \mathrm{g}^{-1}$ at $298 \mathrm{~K}$ for $\mathrm{KOH}$-activated, $\mathrm{ZnCl}_{2}$-activated and sewage sludge (without inorganic activation) adsorbents, respectively. About $99 \%$ of the $\mathrm{Cu}$ (II) was desorbed from $\mathrm{Cu}(\mathrm{II})$-loaded adsorbent using $1.50 \mathrm{~mol} \mathrm{~L}^{-1}$ of $\mathrm{HNO}_{3}$. The regenerated adsorbents were re-utilized for $\mathrm{Cu}$ (II) uptake. It can be inferred that $\mathrm{KOH}$-activated and $\mathrm{ZnCl}_{2}$-activated sewage-sludge adsorbents are effective and alternative adsorbents for removal of $\mathrm{Cu}(\mathrm{II})$ from an aqueous solutions because of their costeffective and considerable adsorption capacities.

\section{Acknowledgments}

The authors are grateful to The National Council for Scientific and Technological Development (CNPq, Brazil); The Coordination of Improvement of Higher Education Personnel (CAPES, Brazil); and Advanced Ceramics Group of Bremen University for financial support, fellowships and technical support.

\section{REFERENCES}

1 Yu MH. Environmental Toxicology- Biological and Health Effects of Pollutants. CRC Press, Boca Raton, 2005.

2 Julio CPV, Eder CL, Betina R, Natali FC. Bruna M, Tatiana C, Pecan Nutshell as Biosorbent to Remove Toxic Metals from Aqueous Solution. Separation Science and Technology, 2014;44(3): 615-644.

3 Ribas MC, Adebayo WA, Prola LDT,Lima EC, Cataluña R, Feris LA, Puchana-Rosero MJ, Machado FM, Pavan FA, Calvete T, Comparison of a homemade cocoa shell activated carbon with commercial activated carbon for the removal of reactive violet 5 dye from aqueous solutions, Chemical Engineering Journal, 2014; 248:315-326.

4 Smith KM, Fowler GD, Pullket S, Graham NDJ, Sewage sludge-based adsorbents: A review of their production, properties and use in water treatment applications. Water Research, 2009; 43: 2569-2594.

5 Adebayo MA, Prola LDT, Lima EC, Puchana-Rosero MJ, Cataluña R, Saucier C, Umpierres CS, Vaghetti JCP, Silva LG, Ruggiero R,Adsorption of Procion Blue MX-R dye from aqueous solutions by lignin chemically modified with aluminium and manganese. Journal of Hazardous Materials, 2014; 268: 43-50.

6 Ros, A., M.A. Lillo-rodenas, E. Fuente, M.A. Montes-moran, M.J. Martin, and A. Linares-solano. 2006. High surface area materials prepared from sewage sludge-based precursors. Chemosphere. 65:132-140.

7 Gasco GB, Guerrero CG, Mendez F, Lazaro AM, The influence of organic matter on sewage sludge pyrolysis. Journal of Analytical Applied of Pyrolisis, 2005;74: 413-420.

8 Seredych M, Bandosz TJ, Removal of copper on composite sewage sludge/industrial sludge-based adsorbents: the role of surface chemistry. Journal of Colloid and Interface Science, 2006; 302: 379-388. 